\title{
Examining Students' Confidence to Learn Online, Self-Regulation Skills and Perceptions of Satisfaction and Usefulness of Online Classes
}

\author{
Brittany Landrum \\ University of Dallas
}

\begin{abstract}
As online class offerings continue to proliferate and more students take at least one online class in college, more research is needed to explore factors that impact students' perceptions of their online classes. Past research has found a positive relationship between students' computer self-efficacy and their satisfaction with online learning, but little research has explored how learning management system and online learning self-efficacy relate to perceptions of satisfaction and perceived usefulness of online classes. In addition to confidence, students must also implement and apply their learning skills in an online environment; thus self-regulation and time management as well as past online learning experience are additional factors that have been shown to be related to satisfaction with and usefulness of online learning. This study explores how students' confidence regarding their ability to use online learning platforms, utilize self-regulation strategies, and their confidence in their ability to learn in online classes predict both their satisfaction with and perceived usefulness of online classes. Multiple regression analyses revealed that students' confidence to learn online was the strongest positive predictor of satisfaction and usefulness of online classes. The results indicate that exploring students' purpose and reasons for taking online classes, beyond a students' skill set and learning strategies, are fruitful directions to pursue when assessing evaluations of online classes.
\end{abstract}

Keywords: online education, satisfaction, usefulness, self-efficacy, self-regulation

Landrum, B. (2020). Examining students' confidence to learn online, self-regulation skills and perceptions of satisfaction and usefulness of online classes. Online Learning, 24(3), 128146. https://doi.org/10.24059/olj.v24i3.2066 


\section{Examining Students' Confidence to Learn Online, Self-Regulation Skills and Perceptions of Satisfaction and Usefulness of Online Classes}

As online courses continue to proliferate, with nearly a third of higher education students in 2017 taking at least one online course and over $15 \%$ of those students enrolled exclusively in online classes (Lederman, 2018), research assessing students' perceptions of this class delivery modality is important. While some students perceive online and face-to-face classes to be equally effective (Horspool \& Lange, 2012) and of similar quality (Waldman, Perreault, Alexander, \& Zhao, 2009), not all students find online courses satisfactory or to be their preferred learning modality. Among students who have taken at least one online course, about $25 \%$ reported being discontented, dissatisfied, and displeased with their online experience while nearly a third reported that online education was an extremely or somewhat poor choice for education and provided poor learning opportunities (Bristow Shepherd, Humphreys, \& Ziebell, 2011). Among business undergraduate students with experience across multiple modalities (face-to-face, online, and hybrid), half of the sample preferred face-to-face classes (Blau, Mittal, Schirmer, \& Ozkan, 2017). In an introductory psychology class, with both in-class and online lectures, students were asked to rate which format (in-class, online, or same) was most helpful: $68 \%$ preferred the in-class format, $63 \%$ enjoyed the in-class material, and $70 \%$ felt the in-class helped them learn the most (Jensen, 2011). These negative attitudes towards online learning raise serious implications about online education.

Among these implications are the different outcomes observed between the two class modalities. In a quasi-experimental study, students enrolled in an online psychology course earned similar grades on all assignments, except scoring significantly lower on a group presentation, compared to those enrolled in a face-to-face version of the class. Both groups reported being satisfied with their respective classes, but the rates of withdrawal and failure were more than twice as high in the online class (Garratt-Reed, Roberts, \& Heritage, 2016). Similar differences were found for community college students enrolled in online math classes who earned significantly lower grades, were less likely to pass and more likely to withdraw compared to students taking face-to-face classes (Francis, Wormington, \& Hulleman, 2019). When examining differences between online students who completed or dropped out of the class, academic locus of control and metacognitive self-regulation were significantly higher among those who completed the online course, but the two groups did not differ on academic self-efficacy, time and environment management, or work/family support (Lee, Choi, \& Kim, 2013). Moreover, students who dropped out of online classes reported being less satisfied (Levy, 2007) and participated significantly less, especially early on in the semester, compared to those who persisted and completed the online course (Nistor \& Neubauer, 2010).

Differences in outcomes and perceptions of online classes might be tied to differences in the modes of delivery, specifically pedagogical and course related factors, as well as self-selection (Garratt-Reed et al., 2016). When evaluating online classes, students report fewer opportunities to interact with the professor and a lack of connectedness and engagement (Bowers \& Kumar, 2015; Dyrbye, Cumyn, Day, \& Heflin, 2009). Other barriers that students face when taking online classes are self-discipline and organizational skills (Kokko, Pesonen, Kontu, \& Pirttimaa, 2015) as well as technological concerns (Dyrbe et al., 2009), especially when the online learning platform is difficult to navigate and feedback is lacking (Gaytan, 2015; Riley \& Schmidt, 2016).

Even if the content and learning outcomes are equivalent (see Garratt-Reed et al., 2016) between the two modalities, how students access and engage with the content online calls for a 
different skill set. Indeed, faculty report that self-discipline is a crucial skill for students to persist and succeed in online classes (Gaytan, 2015). Students are more satisfied with online learning if they generally liked online courses, perceived online courses as an appropriate way of learning, or were somewhat familiar with the course background (Beqiri, Chase, \& Bishka, 2010). Students' satisfaction with online learning also increased with their level of online experience. The current study focuses on student factors that are tied to learning online. Students who struggle with navigating the online platform, gaining access to the course content and who find that online classes call for a different skill set that does not necessarily translate from traditional face-to-face classes may be less satisfied with their online experience and find online classes to be less useful.

\section{Review of Relevant Literature}

Past research exploring factors related to satisfaction with online classes has distinguished between course factors, faculty factors, and student factors (Blackmon \& Major, 2012; Cochran, Baker, Benson, \& Rhea, 2016; Endres, Chowdhury, Frye, \& Hurtubis, 2009). While students' perceptions are tied to an interplay of all these factors, the current study focuses exclusively on student factors, drawing from Zimmerman's model of self-regulated learning (e.g., Zimmerman, 2000; Zimmerman \& Martinez-Pons, 1988), a widely cited and comprehensive social-cognitive theory (see Panadero \& Alonso-Tapia, 2014). This model focuses on students' active agency and use of learning strategies, which are crucial for success (Panadero \& Alonso-Tapia, 2014; Zimmerman, 2008). Zimmerman describes three phases that students undertake when performing a task: forethought, performance, and self-reflection. During forethought, students first evaluate and assess the task in light of their goals and expectations. Students evaluate their interest, purpose and ability to complete the task. During performance, students utilize learning strategies and techniques to help them achieve their goals. During self-reflection, students evaluate their performance and reaction to the task.

Students' initial goals, expectations, and interests in the class comprise the forethought planning phase that has been shown to be influential for successful outcomes (Zimmerman, 2008). After this initial evaluation phase, students' own beliefs about their abilities influence their motivation and use of learning strategies to achieve their goals. According to Zimmerman, Schunk, and DiBenedetto (2017), students' sense of agency is an important characteristic of success. Students' use of self-regulation learning strategies is tied to their perceived ability or confidence to adopt them. Thus, Zimmerman et al. propose a cyclical process between self-efficacy and selfregulation processes. Indeed, for undergraduate students enrolled in a flipped math course, selfefficacy to learn math and students' adoption of help seeking strategies were positively related to performance (Sun, Xie, \& Anderman, 2018). Moreover, students assigned to a teaching intervention designed to enhance self-regulation demonstrated higher self-efficacy, timemanagement, and help-seeking behaviors in comparison to a control group (Lai, Hwang, \& Tu, 2018).

Because the sample in the current study comprises students currently enrolled in an online class at one point in time, the current study could not explore students' initial reasons, interests, or purposes for enrolling in an online class nor how these elements of Zimmerman's model progress or change over the course of a semester. Instead, the current study focuses on students' beliefs about their abilities (self-efficacy) and their use of learning strategies (self-regulation) to evaluate how these relate to perceptions of both satisfaction and usefulness. The following sections review 
past research on self-efficacy and self-regulation within online learning and lastly considers research on online learning experience.

\section{Self-efficacy}

One of the ways researchers have explored students' ability to navigate online classes is by measuring students' self-efficacy. Self-efficacy refers to one's confidence in their ability to accomplish a certain task (Bandura, 1986) and is best defined and measured with specific reference to the domain or task being investigated (Pajares, 1996). When applied to online learning, selfefficacy has mostly focused on the technology aspects and studied in three main ways: computer self-efficacy, internet and information-seeking self-efficacy, and lastly e-learning management system (LMS) self-efficacy (Alqurashi, 2016).

Computer and Internet Self-efficacy. The first two types of self-efficacy, computer and internet, refer to one's confidence to use computers and use the internet to search for information. Research has mostly found a positive relationship between computer self-efficacy and satisfaction with online learning (e.g., Hammouri \& Abu-Shanab, 2018; Jung, 2014; Kırmız1, 2015; Lee \& Hwang, 2007; Lim, 2001; Wu, Tennyson, \& Hsia, 2010; Yimaz, 2017) as well as a positive relationship with perceived ease of use and usefulness of online research databases (Chen, Islam, Gu, Teo, \& Peng, 2019; Islam, Leng, \& Singh, 2015). However, some research has not found a significant relationship between computer self-efficacy and satisfaction (Jan, 2015) or motivation to learn online (Simmering, Posey, \& Piccoli, 2009).

Regarding the internet, research has shown moderate to weak significant positive correlations between internet self-efficacy and satisfaction (Chu, 2010; Kuo \& Belland, 2016; Kuo, Walker, Belland, \& Schroder, 2013). When included with other predictors in a regression analysis, internet self-efficacy positively predicted student satisfaction (Kuo et al., 2013), but not significantly in other studies (Al-Azawei \& Lundqvist, 2015; Kuo, Walker, Schroder, \& Belland, 2014). While students scoring high on computer self-efficacy reported greater confidence and relevance of online courses compared to those low on computer self-efficacy, these two groups did not significantly differ on satisfaction with online courses (Chang et al., 2014). Overall, research has shown that one's confidence to use a computer and the internet, in general, are related to satisfaction, but these two variables do not specifically measure a student's ability to use a computer and the internet to take an online class.

LMS Self-efficacy. The last technology aspect of self-efficacy focuses on the online learning platform itself and thus assesses a student's ability to specifically navigate and access the online learning material on a computer. While knowing how to use a computer and the internet are important skills when taking an online class, the class itself is typically delivered on a platform that can either facilitate or hinder access to the course material (Martin, Tutty, \& Su, 2010). Research on LMS self-efficacy is scarce (Alqurashi, 2016) and when it is considered, some researchers will combine it with general technology self-efficacy (e.g., Wang, Shannon, \& Ross, 2013). When validating a scale to measure LMS self-efficacy, Bradley, Browne, and Kelley (2017) found a moderate positive correlation with internet self-efficacy, suggesting these technology aspects are related but distinct. Despite the importance of the online platform in delivering course content and enabling students to gain access to it using a skill set that goes beyond using a computer and the internet, little research has focused exclusively on this aspect.

When asking students what they value most in an online learning environment, Palmer and Holt (2010) identified the following elements of an online learning system as being the most valued 
by students: accessing course information, interacting with online resources, participating in online discussions, and contacting lecturers and tutors. Indeed, if these are most valued by students and perceived as contributing to an enhanced learning experience, students must have confidence in their ability to use these elements of the online platform. In support of this, one's confidence to communicate and learn online was a significant and positive predictor of satisfaction with online learning (Palmer \& Holt, 2009). LMS self-efficacy was higher among online students compared to hybrid students, but was only a significant positive predictor of course performance for the latter group (Martin et al., 2010). Being able to use and navigate the online platform seems to be a crucial element of taking an online course and succeeding; more research is needed to explore how confidence using the online platform is related to other perceptions, including satisfaction and usefulness. Therefore, this study will add to this literature by exploring students' confidence to use the online learning platform rather than assessing confidence to use the computer or Internet.

Self-efficacy to Learn Online. While most of the literature on self-efficacy in online education focuses on the technology aspects, there are other dimensions of self-efficacy that are important to consider. Out of five separate components of self-efficacy explored in online classes, a multiple regression revealed that self-efficacy to handle the online platform tools (i.e., LMS selfefficacy) was not a significant predictor of students' satisfaction with online learning (Shen, Cho, Tsai, \& Marra, 2013). However, the other four components (self-efficacy to complete an online course, interact both socially and academically with peers, and interact with the instructors) were all positive significant predictors of satisfaction with online learning. A student may feel confident in their ability to use the technology in an online course (use a computer and the internet as well as navigate the online learning platform), but these technology-focused aspects of self-efficacy do not capture students' reasons for taking a class or the purpose of choosing an online class. One reason to take a class is to learn and take something away from the class. Self-efficacy to learn online captures how confident students are about their ability to learn in an online, asynchronous environment in the absence of both peers and the instructor and has been tied to a number of outcomes.

Specifically, self-efficacy to learn online was the strongest predictor of perceived learning (Alqurashi, 2019) and students' self-reported self-efficacy to learn math asynchronously positively predicted math achievement throughout the semester (Hodges, 2008). Moreover, self-efficacy to learn online was a negative predictor of both frustration and boredom in online classes (Artino \& McCoach, 2008) and a significant positive predictor of students' satisfaction with their online class experiences (Alqurashi, 2019; Artino, 2008; Y.-M. Lin, Lin, \& Laffey, 2008). Online learning selfefficacy was positively and significantly correlated with satisfaction, achievement as well as persistence in online classes (Joo, Lim, \& Kim, 2013). Thus, in addition to focusing on selfefficacy to use the online platform, this study will also contribute to this growing body of literature exploring self-efficacy to learn online.

\section{Self-regulation}

Students' self-efficacy to use the online learning platform and learn in online classes are both important, but students must also adopt learning strategies to be successful. Self-regulation refers to the ability to use self-managing behaviors and implement learning processes (Zimmerman, 1995a) that, when coupled with motivation, enable students independently to put their self-confidence beliefs into action (Zimmerman, 1995b). These self-regulation behaviors and the confidence to be able to implement them in an online learning environment are related to a number of outcomes. Compared to students who persisted, self-regulation skills were significantly 
lower among students who dropped out of online courses (Lee et al., 2013). Furthermore, selfregulation skills were positively correlated with academic outcomes (Broadbent \& Poon, 2015), positive attitudes towards online learning and perceived usefulness of collaborative online learning activities (Su, Li, Liang, \& Tsai, 2018). In contrast, other studies found student self-regulation did not significantly predict satisfaction in online courses or learning outcomes when included in structural equation models or multiple regressions (Eom \& Ashill, 2016; Kuo et al., 2013).

Bradley et al. (2017) found that their newly created LMS self-efficacy scale was strongly positively correlated with self-regulation, suggesting these are closely related and interdependent constructs. According to Lee and Hwang's (2007) e-learning effectiveness model, both selfefficacy and self-regulatory learning strategies are important for perceived satisfaction and usefulness of online classes. Some studies have found these two constructs relate to outcomes similarly. Eom (2012) found that self-regulation and LMS self-efficacy were positively correlated but neither significantly predicted satisfaction with the online learning platform. Liaw and Huang (2013) found LMS self-efficacy and self-regulation were moderately positively correlated with each other and both were related positively with LMS satisfaction and usefulness. Yet, researchers have found that these two constructs do relate to outcomes differently. Self-regulation was connected with higher levels of student engagement in online classes, but computer self-efficacy was not (Sun \& Rueda, 2012). Based on these inconsistent findings, this study will jointly explore both self-efficacy and self-regulation as predictors of satisfaction and usefulness.

\section{Past Experience}

Students' self-efficacy and self-regulation behaviors might improve over time with more experience in online classes. Students with more online class experience report higher self-efficacy to learn online (Artino, 2008; Bradley et al., 2017) and use more self-regulation and effective learning strategies (Bradley et al., 2017; Wang et al., 2013). In addition, students with past online experience report greater satisfaction (Artino, 2008; Jan, 2015) and more positive learning experiences in online classes (Li, Marsh, Rienties, \& Whitelock, 2017). The use of effective learning strategies along with technology self-efficacy acted as mediators for the relationship between past online experience and satisfaction (Wang et al., 2013). Online class experience might alter how self-efficacy and self-regulation strategies relate to both satisfaction and perceived usefulness of online learning. Among students with high and low online class experience, students' confidence and use of learning strategies might relate differently with perceived satisfaction and usefulness of online classes.

\section{Current Study}

The current study answers the call for more research into self-efficacy within online learning (Alqurashi, 2016), specifically exploring two less studied aspects of self-efficacy: online learning platform and learning online. This project aims to explore how students' confidence regarding their ability to use online learning platforms, utilize self-regulation strategies, and their ability to learn in online classes predict both their satisfaction with and perceived usefulness of online classes. Moreover, these initial relationships might be moderated by online class experience. Specifically, this study answers the following questions: to what extent do LMS self-efficacy, selfefficacy to learn online, and self-regulation measures, both alone and in combination, relate to perceived satisfaction with the online platform, satisfaction with online learning and usefulness of online learning and which of these predictors is the strongest? Does past online learning experience interact with any of the significant relationships found in the multiple regression analyses? 


\section{Methods}

\section{Sample}

A total of $N=88$ undergraduate and graduate students currently enrolled in an online psychology class, 72 females (81.82\%), from two universities in Texas completed the survey. One university is a small private religiously affiliated school and the other university is a small state school. Students were offered minimal extra credit for participating. Students' average age was $28.7(S D=8.54)$, ranging from 18 to 50 . Roughly half of the sample $(48.9 \%)$ was between the ages of 18-25. On average, students had taken $8.95(S D=8.38)$ online classes, ranging from 1 to 40. This research was approved by the institutional review boards.

\section{Survey}

Participants answered demographic questions (sex and age) as well as reported the number of online classes they have taken or are currently taking as a measure of online experience. Then they completed a 57-item survey to measure self-efficacy, self-regulation, satisfaction, and usefulness concerning online classes.

\section{Predictors}

Self-efficacy. Two scales measured self-efficacy. First, self-efficacy to use the online learning platform (LMS self-efficacy) was measured using the 13-item scale from the Online Academic Success Indicators Scale (OASIS; Bradley et al., 2017). Sample items included students' confidence to "upload an assignment" and "take a test or quiz online" and thus captures students' confidence in their ability to navigate and utilize the online learning platform effectively to interact with the online material. Students rated their confidence on a 7 -point scale $(1=$ not confident to $7=$ very confident).

In addition to being able to use the online platform to gain access to the course content, students also have beliefs about their ability to learn in an online environment (self-efficacy for learning). Thus, students' confidence regarding their ability to learn online was measured using the 7-item scale from the Online Learning Self-Efficacy Scale (OLSES; Zimmerman \& Kulikowich, 2016). Sample items included students' confidence to learn "without being in the same room as the instructor" and "communicate using asynchronous technologies" thus measuring how confident students are about learning online. Students rated their confidence on a 6-point scale $(1=$ not at all confident to $6=$ complete confidence $)$.

Self-regulation Efficacy. Two scales were used to measure self-regulation strategies. First, students' self-efficacy for time management was measured using the 5-item scale from OLSES (Zimmerman \& Kulikowich, 2016). This scale, referred to as time management regulation, measures students' confidence to "manage time effectively" and "develop and follow a plan for completing all required work on time." Students rated their confidence on a 6 -point scale $(1=$ not at all confident to $6=$ complete confidence).

Students are not only facing time management concerns but also need to have the ability to ask for help when they need it and utilize external resources to help them succeed in online courses. These additional self-regulation strategies are captured in the scale self-regulation learning strategies in online courses, a 10-item scale from the OASIS (Bradley et al., 2017). Sample items included students" confidence to "maintain focus on an assigned task" and "ask for help from your online peers." Students rated their confidence on a 7-point scale $(1=$ not confident to $7=$ very confident). 


\section{Outcomes}

Perceived satisfaction was measured using two scales. First, satisfaction with the online platform was measured using a 5-item scale (Liaw \& Huang, 2013) assessing students' satisfaction with several elements of the online platform and learning content. Sample items included being satisfied with "using e-learning functions" and "multimedia instruction." Students rated their satisfaction on a 7-point scale ( $1=$ strongly disagree to $7=$ strongly agree $)$.

Second, satisfaction with online learning was measured using an 11-item scale (Zakariah, Hashim, \& Musa, 2016) assessing students' satisfaction with online learning. This scale measures how satisfied students are with their online learning in general as well as compared to face-to-face classes. Sample items included "I enjoy learning from the web based lessons" and "I prefer web based courses to traditional classroom instruction." Students rated their satisfaction on 7-point scale $(1=$ extremely dissatisfied to 7 = extremely satisfied).

For perceived usefulness of online classes, a 6-item scale (Liaw \& Huang, 2013) was used to measure how useful online classes are in terms of their effectiveness and as an aid in learning. Sample items included the belief that "e-learning systems are useful learning tools" and students' intention to: "use e-learning content to assist my learning." Students rated these items on a 7-point scale $(1=$ strongly disagree to $7=$ strongly agree $)$.

\section{Statistical Analysis}

To answer the first research question, a correlation matrix was run with all the variables to detect how measures of self-efficacy and self-regulation individually relate to satisfaction and usefulness. Then ordinary least squares multiple regression analyses were run for each of the three outcome variables (two satisfaction measures and one usefulness measure) to discern which predictor was the strongest; each regression had five predictors: number of online classes, LMS self-efficacy, confidence to learn online, time management regulation, and self-regulation learning strategies. To test the possible moderating effect (Baron \& Kenny, 1986) of past online experience, an interaction term was created with only the significant predictors from the three regression analyses.

\section{Results}

First, a Pearson correlation matrix was run between all of the variables to investigate how measures of self-efficacy and self-regulation individually relate to satisfaction and usefulness. There were strong to moderate correlations between most of the variables (see Table 1) indicating that the more confidence one has to use the online platform, to learn online, to use self-regulation strategies, and manage one's time, the more satisfied one is with the online platform and with learning online as well as perceiving online classes to be useful. Additionally, both measures of self-efficacy were strongly positively correlated with both measures of self-regulation learning strategies. 
Examining Students' Confidence to Learn Online, Self-Regulation Skills and

Perceptions of Satisfaction and Usefulness of Online Classes

Table 1

Pearson Correlations and Alpha Coefficients for all Measures

\begin{tabular}{|c|c|c|c|c|c|c|c|c|c|}
\hline & & 1 & 2 & 3 & 4 & 5 & 6 & 7 & 8 \\
\hline 1. \# online classes & $\begin{array}{l}\text { Pearson's r } \\
\text { p-value }\end{array}$ & - & & & & & & & \\
\hline 2. LMS SE & $\begin{array}{l}\text { Pearson's r } \\
\text { p-value }\end{array}$ & $\begin{array}{r}0.084 \\
0.437\end{array}$ & .95 & & & & & & \\
\hline 3. SE learn & $\begin{array}{l}\text { Pearson's r } \\
\text { p-value }\end{array}$ & $\begin{array}{r}0.118 \\
0.273\end{array}$ & $\begin{array}{l}0.853 * * * \\
<.001\end{array}$ & $\begin{array}{r}.908 \\
-\end{array}$ & & & & & \\
\hline 4. SR time & $\begin{array}{l}\text { Pearson's r } \\
\text { p-value }\end{array}$ & $\begin{array}{r}0.101 \\
0.349\end{array}$ & $\begin{array}{l}0.841 * * * \\
<.001\end{array}$ & $\begin{array}{l}* 0.841 * * * \\
<.001\end{array}$ & $\begin{array}{r}.912 \\
-\end{array}$ & & & & \\
\hline 5. SR & $\begin{array}{l}\text { Pearson's r } \\
\text { p-value }\end{array}$ & $\begin{array}{r}0.079 \\
0.463\end{array}$ & $\begin{array}{l}0.902 * * * \\
<.001\end{array}$ & $\begin{array}{l}* 0.807 * * * \\
<.001\end{array}$ & $\begin{array}{l}0.856 * * * \\
<.001\end{array}$ & * $\begin{array}{r}.902 \\
-\end{array}$ & & & \\
\hline 6. Satisfaction online platform & $\begin{array}{l}\text { Pearson's r } \\
\text { p-value }\end{array}$ & $\begin{array}{c}0.210 * \\
0.050\end{array}$ & $\begin{array}{c}* 0.560 * * * \\
<.001\end{array}$ & $\begin{array}{l}* 0.662 * * * \\
<.001\end{array}$ & $\begin{array}{l}0.568 * * * \\
<.001\end{array}$ & $\begin{array}{l}* 0.623 * * * \\
<.001\end{array}$ & $\begin{array}{r}.922 \\
-\end{array}$ & & \\
\hline 7. Satisfaction online learning & $\begin{array}{l}\text { Pearson's r } \\
\text { p-value }\end{array}$ & $\begin{array}{c}0.243 * \\
0.023\end{array}$ & $\begin{array}{c}* 0.475 * * * \\
<.001\end{array}$ & $\begin{array}{c}* 0.568 * * * \\
<.001\end{array}$ & $\begin{array}{l}0.516 * * * \\
<.001\end{array}$ & $\begin{array}{c}* 0.483 * * * \\
<.001\end{array}$ & $\begin{array}{l}0.710 * * * \\
<.001\end{array}$ & $\begin{array}{r}.917 \\
-\end{array}$ & \\
\hline 8. Usefulness & $\begin{array}{l}\text { Pearson's r } \\
\text { p-value }\end{array}$ & $\begin{array}{r}0.202 \\
0.060\end{array}$ & $\begin{array}{l}0.482 * * * \\
<.001\end{array}$ & $\begin{array}{l}* 0.557 * * * \\
<.001\end{array}$ & $\begin{array}{l}0.504 * * * \\
<.001\end{array}$ & $\begin{array}{l}* 0.530 * * * \\
<.001\end{array}$ & $\begin{array}{l}0.884 * * * \\
<.001\end{array}$ & $\begin{array}{l}=0.743 * * * \\
<.001\end{array}$ & .948 \\
\hline
\end{tabular}

$* p<.05, * * p<.01, * * * p<.001$

Note. Cronbach's alpha coefficients are reported on the diagonal. 1. \# of online classes is the number of online classes students have taken or currently taking; 2. LMS SE measures students' self-efficacy to use and navigate online courses using the learning management platform; 3. SE learn measures students' self-efficacy to learn online; 4. SR time measures students' time management regulation; 5. SR measures students' use of self-regulated learning strategies online; 6 . Satisfaction online platform measures perceived satisfaction with the online learning platform; 7. Satisfaction online learning measures perceived satisfaction with learning online; 8. Usefulness measures perceived usefulness of online classes.

To discern how these variables together predict the three perceptions, three multiple regression analyses were conducted. Given the moderate to strong correlations between the predictors, the tolerance and VIF values are provided in Table 2 below. Number of online classes had the highest tolerance value (.984) indicating it has the potential to provide the greatest amount of unique predictive information. Multicollinearity was a concern for the remaining predictor variables which had lower tolerance values and higher VIF values. These values indicate that the proportion of variance not already attributable to the other predictors was much lower and thus these variables are contributing less unique predictive information. The first regression analysis predicted satisfaction with the online platform. All five predictors accounted for $50.7 \%$ of the variation in this measure of satisfaction, $F(5,82)=16.9, p<.001$ (see Table 2 ).

Table 2

Multiple Regression Predicting Satisfaction with the Online Platform

\begin{tabular}{rccccccc}
\hline \multicolumn{1}{c}{ Predictors } & Unstandardized & SE & Standardized & $\mathbf{t}$ & $\mathbf{p}$ & Tolerance & VIF \\
\hline Constant & 1.998 & .476 & & 4.201 & $<.001$ & & \\
\# online classes & 0.018 & 0.010 & 0.137 & 1.748 & 0.084 & .984 & 1.016 \\
LMS SE & -0.396 & 0.208 & -0.393 & -1.901 & 0.061 & .140 & 7.128 \\
SE learn & $\mathbf{0 . 7 4 0}$ & $\mathbf{0 . 1 9 2}$ & $\mathbf{0 . 6 3 8}$ & $\mathbf{3 . 8 5 0}$ & $<.001$ & $\mathbf{. 2 1 9}$ & $\mathbf{4 . 5 7 0}$ \\
SR time & -0.157 & 0.186 & -0.146 & -0.842 & 0.402 & .201 & 4.979 \\
SR & $\mathbf{0 . 5 5 9}$ & $\mathbf{0 . 1 9 1}$ & $\mathbf{0 . 5 7 7}$ & $\mathbf{2 . 9 2 8}$ & $\mathbf{0 . 0 0 4}$ & $\mathbf{. 1 5 4}$ & $\mathbf{6 . 4 7 4}$ \\
\hline
\end{tabular}

Note. \# of online classes is the number of online classes students have taken or currently taking; LMS SE measures students' selfefficacy to use and navigate online courses using the learning management platform; SE learn measures students' self-efficacy to learn online; SR time measures students' time management regulation; SR measures students' use of self-regulated learning strategies online; Satisfaction with the online platform measures perceived satisfaction with the online learning platform. 
There were only two significant predictors for perceived satisfaction with the online platform: self-regulated learning strategies and self-efficacy to learn online. Students were more satisfied with the online learning platform when they reported higher self-reported ability to selfregulate online (e.g., maintaining focus, asking for help) and higher confidence to learn online.

The second regression analysis predicted satisfaction with online learning. All five predictors accounted for $36.4 \%$ of the variation in this measure of satisfaction, $F(5,82)=9.37, p$ $<.001$ (see Table 3).

Table 3

Multiple Regression Predicting Satisfaction with Online Learning

\begin{tabular}{rccccc}
\hline \multicolumn{1}{c}{ Predictors } & Unstandardized & SE & Standardized & t & P \\
\hline Constant & 1.44 & .595 & & 2.42 & .018 \\
\# online classes & $\mathbf{0 . 0 2 5}$ & $\mathbf{0 . 0 1 3}$ & $\mathbf{0 . 1 7 6}$ & $\mathbf{1 . 9 8 7}$ & $\mathbf{0 . 0 5 0}$ \\
LMS SE & -0.196 & 0.261 & -0.177 & -0.753 & 0.454 \\
SE learn & $\mathbf{0 . 6 3 0}$ & $\mathbf{0 . 2 4 1}$ & $\mathbf{0 . 4 9 3}$ & $\mathbf{2 . 6 1 7}$ & $\mathbf{0 . 0 1 1}$ \\
SR time & 0.155 & 0.233 & 0.131 & 0.667 & 0.507 \\
SR & 0.126 & 0.239 & 0.119 & 0.529 & 0.598 \\
\hline
\end{tabular}

Note. \# of online classes is the number of online classes students have taken or currently taking; LMS SE measures students' selfefficacy to use and navigate online courses using the learning management platform; SE learn measures students' self-efficacy to learn online; SR time measures students' time management regulation; SR measures students' use of self-regulated learning strategies online; satisfaction with online learning measures perceived satisfaction with learning online.

There were only two significant predictors of perceived satisfaction with online learning: number of online classes and self-efficacy to learn online. As online class experience and confidence in one's ability to learn online increased, students reported being more satisfied with learning online.

The third regression analysis predicted usefulness of online classes. All five predictors accounted for $36 \%$ of the variation in usefulness, $F(5,82)=9.24, p<.001$ (see Table 4 ).

Table 4

Multiple Regression Predicting Usefulness of Online Classes

\begin{tabular}{rcccccc}
\hline Predictors & Unstandardized & SE & Standardized & t & 3.369 & .001 \\
Constant & 2.051 & .609 & & 0.140 & 1.568 & 0.121 \\
\# online classes & 0.020 & 0.013 & 0.267 & -0.291 & -1.234 & 0.221 \\
LMS SE & -0.329 & $\mathbf{0 . 2 4 6}$ & $\mathbf{0 . 4 5 7}$ & $\mathbf{2 . 4 2 2}$ & $\mathbf{0 . 0 1 8}$ \\
SE learn & $\mathbf{0 . 5 9 6}$ & 0.238 & -0.009 & -0.043 & 0.966 \\
SR time & -0.010 & 0.244 & 0.420 & 1.867 & 0.065 \\
SR & 0.456 &
\end{tabular}

Note. \# of online classes is the number of online classes students have taken or currently taking; LMS SE measures students' selfefficacy to use and navigate online courses using the learning management platform; SE learn measures students' self-efficacy to learn online; SR time measures students' time management regulation; SR measures students' use of self-regulated learning strategies online; usefulness measures perceived usefulness of online classes. 
There was only one significant predictor of perceived usefulness: self-efficacy to learn online. The higher confidence students had regarding their ability to learn online, the higher the perceived usefulness of online classes.

Next, past online experience (number of online classes) was tested as a possible moderator of the relationship between the significant predictors of each of the three outcomes (self-regulated learning strategies and the outcome satisfaction with online platform; self-efficacy to learn online and each of the three outcomes). The predictors and moderator variables were grand-mean centered to control for multicollinearity. However, the interaction term (predictor x number of online classes) was not significant in any of the four regression analyses.

While past online experience did not significantly moderate the relationship between selfefficacy to learn online and satisfaction with online learning, a between-groups test was run to replicate findings reported in the literature. A $t$-test was run to examine differences in the outcome measures between those who had taken a high versus low number of online classes, as one measure of experience with this modality. A median split was used to create the two groups with those at the median (i.e., 6) categorized into the low group. The only significant difference was on satisfaction with online learning. Those who had taken between 7 and 40 online classes (high experience, $n=40)$ reported significantly higher satisfaction with their learning $(M=5.42)$ compared to those who had taken between 1 and 6 online classes $(M=4.77$; low experience, $n=$ $48), t(86)=-2.64, p=.01, d=-0.564$. The effect size indicated this was a moderate sized difference.

\section{Discussion}

The current study sought to examine how students' confidence (self-efficacy measures) and use of learning strategies (self-regulation measures) relate to students' perceptions of online classes. The correlation analysis revealed positive and significant correlations between LMS selfefficacy, learning self-efficacy, self-regulation, and time management with perceived satisfaction and usefulness. Specifically, satisfaction with the online platform was higher for students who reported greater confidence to learn online and adoption of online learning strategies. The LMS platform is more satisfactory when students are confident in their ability to learn online and have the skills necessary to implement this ability. Greater satisfaction with online learning was reported by those who had more experience with online classes and were more confident in their ability to learn online. Additionally, online classes were perceived as more useful when students reported greater confidence to learn online.

The strong correlations between the predictor variables and the relatively low tolerance values indicate that multicollinearity is a concern making it difficult to isolate the unique effects of each variable in the regression models. Similar to other studies, the predictor variables were significantly correlated with the outcomes individually but not when combined in multiple regression analyses. Specifically, LMS self-efficacy, when compared to other predictors, lacked a significant relationship with satisfaction and usefulness, supporting Eom (2012) and Shen et al. (2013). Self-regulation strategies were not significant predictors of satisfaction with learning or usefulness, supporting Eom and Ashill (2016) and Kuo et al. (2013). While there was a strong positive correlation between LMS self-efficacy and self-regulation strategies, supporting other researchers' findings (Bradley et al., 2017; Eom, 2012; Liaw \& Huang, 2013), and despite the positive correlations with satisfaction and usefulness (supporting Liaw \& Huang, 2013; Su et al., 
2018), confidence in one's ability to use the online platform and adopt learning strategies online lacked a significant predictive relationship with learning satisfaction and usefulness. The concerns with multicollinearity call into question the ability to identify the strongest predictor and perhaps rather than trying to isolate a single variable responsible for students' perceptions (see Hobson \& Puruhito, 2018), the current study reveals that there are many variables related to satisfaction and usefulness. As the correlations revealed, confidence and learning strategies were correlated with each other and related to students' perceptions of online classes. A path analysis model might better capture the interrelatedness of these constructs to explore how these student factors, combined with faculty and course factors (e.g., Cochran et al., 2016; Endres et al., 2009; Kucuk \& Richardson, 2019), relate to each other as well as with various outcomes.

The strong, positive, and significant correlations between the measures of self-efficacy and the use of self-regulation strategies provide support for Zimmerman's self-regulation learning model (2000) and Lee and Hwang's (2007) e-learning effectiveness model. Students who are more confident in their use of the LMS and their ability to learn online are also adopting and practicing skills and strategies in their online classes. Given that all the variables were measured at the same time, the cyclical nature of Zimmerman's model could not be explored in this study. The multicollinearity in this study points to the interrelatedness of the variables and the complexity of students' perceptions. Future research could measure these variables multiple times during a semester to better capture the interrelationships between and amongst these variables.

This study adds to the growing body of literature exploring LMS self-efficacy finding a positive and strong correlation with satisfaction with the online platform and online learning (see Palmer \& Holt, 2009) as well as usefulness of online classes. This study also supports the positive relationships found between online learning self-efficacy with satisfaction, learning, and academic outcomes (Alqurashi, 2019; Artino, 2018; Hodges, 2008; Joo et al., 2013; Lin et al., 2008). Moreover, there was a strong positive correlation between both measures of self-efficacy: LMS and to learn online. Both of these dimensions seem important for achieving one's goals and successfully completing an online class. Future research exploring multiple dimensions of students' self-efficacy are fruitful directions to pursue, particularly exploring how they might relate to the self-reflection phase of Zimmerman's model.

When students feel capable and confident in their ability to learn and take something away from the class, they are more satisfied with their experiences and thus at a lower risk of dropping out (Levy, 2007). This also means that if the students have less confidence in their ability to learn by taking online classes, they perceived online classes as being less useful and were more dissatisfied with both the platform and learning online. Thus, a student needs to have confidence that one can learn in order for the online classes to be perceived as useful. If a student feels they are not going to learn anything, then the classes are not useful and perceived as a waste of time. This might also contribute to the lower rate of participation seen in those who drop out of online classes (Nistor \& Neubauer, 2010); the issue may not be one of not knowing how to use the technology (technology self-efficacies) or effectively carrying out the task (self-regulation), but rather one of lacking a learning objective. Indeed, research exploring students' perceptions of faculty factors has found that students were more satisfied with their online classes when teachers were perceived as providing direction and clear expectations (Jackson, Jones, \& Rodriguez, 2010). Thus, future research should assess not only students' confidence to learn but also their sense of the guidance and direction offered by the teacher. 
Prior experience was correlated with satisfaction with the platform and online learning, but only had a predictive relationship with the latter. Unlike Jan (2015), this study found that prior experience did retain a significant relationship with online learning satisfaction when included in a multiple regression analysis. Prior experience was not found to moderate the relationship between self-efficacy to learn online and online learning satisfaction. Using a median split to categorize number of online classes into those with high versus low experience, this study found the only significant difference was satisfaction with online learning. As students gain more experience with this online modality, they report being more satisfied with their learning through this online modality. Given that it was unrelated to confidence using the platform, or being able to use effective learning strategies, this suggests these are not being learned over time or with additional experience but could perhaps be tied to familiarity with using computers and being online in everyday life (separate from school) or based on training that is offered by the schools (help, support, how to take an online class, etc.; see Lai et al., 2018). The current study did not support Bradley et al.'s (2017) finding that students with more online experience reported higher self-efficacy to learn and self-regulation, but it should be noted that Bradley et al. compared students with zero or one online class to those with two or more. Perhaps students are able to learn these strategies and become confident after just a few online classes, but the lack of a correlation in this study would suggest this was not the case. More research should investigate self-efficacy and self-regulation among students with no online class experience and those with more experience. However, this study did reveal that students with more online class experience are more satisfied with online learning than those with less experience. While the use of strategies and confidence may not differ, satisfaction with learning appears to improve with more experience.

The results of this study should be considered in light of the limitations of the convenience sample that comprised students taking psychology classes and thus the results may not be generalizable to all students. Additionally, very few males responded and while this proportion of males is not unusual among psychology classes, future research should attempt to survey a more representative sample of college students. Considering the wide range of ages represented in this sample, future research could investigate if traditional and nontraditional students differ in their perceptions and experiences with online courses. The measure of past experience with online classes only considered how many online classes the students had taken or were currently taking and did not measure their experience with those classes. The sample of students could have had a wide range of experiences with online classes, taught at multiple universities and by multiple teachers. Not all online classes are the same and future research can explore how specific elements and factors of online classes are perceived by students.

The current study only investigated a narrow range of student factors limited to LMS efficacy and learning skills. Students rated their overall experience with online classes, rather than a particular class, thus identifying specific course elements, course design, or pedagogical techniques was not possible. Given the wide range of course designs and varying experiences with online classes, the results only shed light on overall ratings of satisfaction and how these are associated with a handful of student factors. The focused analysis on LMS efficacy in the current study did not consider other student factors that past research has indicated are important, including students' agency and expectations regarding the class (see Dziuban et al., 2015). Based on past research showing that students' positive perceptions of online classes were tied to both technology efficacy and interactions with both content and instructors (Kuo et al., 2013), future research should explore these opportunities for interactions and expand the scope to consider course and faculty factors as well (Blackmon \& Major, 2012; Cochran et al., 2016; Endres et al., 2009). 
According to an analysis of focus groups, Parahoo et al. (2016) found that students' interactions with classmates, faculty and staff were important dimensions of the students' experienced satisfaction. Moreover, students' perceptions of the teacher (e.g., availability, clear expectations, comfortable atmosphere) are positively related with students' satisfaction (Jackson et al., 2010). Likewise, a structural equation model revealed teaching presence to be the primary factor related to student satisfaction (Kucuk \& Richardson, 2019). As the current study highlights the importance of students' self-efficacy to learn online, additional research should also explore the collaborative aspects of taking a course, along with the students' expectations and perceptions of the teacher, to shed more light on perceptions of online classes.

Future research should also explore other factors related to students' motivations for taking an online class that were not considered here. These include the ability to choose the modality where students self-select their preferred format if the class has multiple format offerings. Students may find the online modality more convenient and suited to life circumstances (e.g., working fulltime, taking care of young children), which might render the flexibility afforded by online classes appealing (see Dyrbye et al., 2009; Kokko et al., 2015). Discerning other motivations to take an online class could expand on past qualitative studies exploring students' experiences of satisfying and unsatisfying online classes. Further exploration into the interrelatedness and cyclical relationship between confidence and self-regulation would help to address the high drop-out rate and help improve overall experiences with online classes. 


\section{References}

Al-Azawei, A., \& Lundqvist, K. (2015). Learner differences in perceived satisfaction of an online learning: An extension to the technology acceptance model in an Arabic sample. Electronic Journal of E-Learning, 13(5), 408-426.

Alqurashi, E. (2016). Self-efficacy in online learning environments: A literature review. Contemporary Issues in Education Research, 9(1), 45-51.

Alqurashi, E. (2019). Predicting student satisfaction and perceived learning within online learning environments. Distance Education, 40(1), 133-148.

Artino, A. R. (2008). Motivational beliefs and perceptions of instructional quality: Predicting satisfaction with online training. Journal of Computer Assisted Learning, 24(3), 260-270.

Artino, A. R., Jr., \& McCoach, D. B. (2008). Development and initial validation of the Online Learning Value and Self-Efficacy Scale. Journal of Educational Computing Research, 38(3), 279-303.

Bandura, A. (1986). The explanatory and predictive scope of self-efficacy theory. Journal of Social and Clinical Psychology, 4(3), 359-373.

Baron, R. M., \& Kenny, D. A. (1986). The moderator-mediator variable distinction in social psychological research: Conceptual, strategic and statistical considerations. Journal of Personality and Social Psychology, 51, 1173-1182.

Blackmon, S. J., \& Major, C. (2012). Student experiences in online courses: A qualitative research synthesis. Quarterly Review of Distance Education, 13(2), 77-85.

Blau, G., Mittal, N., Schirmer, M., \& Ozkan B. (2017). Differences in business undergraduate perceptions by preferred classroom learning environment. Journal of Education for Business, 92(6), 280-287.

Bowers, J., \& Kumar, P. (2015). Students' perceptions of teaching and social presence: A comparative analysis of face-to-face and online learning environments. International Journal of Web Based Learning and Teaching Technologies, 10, 27-44. doi: 10.4018/ijwltt.2015010103

Bradley, R. L., Browne, B. L., \& Kelley, H. M. (2017). Examining the influence of self-efficacy and self-regulation in online learning. College Student Journal, 51(4), 518-530.

Bristow, D., Shepherd, C. D., Humphreys, M., \& Ziebell, M. (2011). To be or not to be: That isn't the question! An empirical look at online versus traditional brick-and-mortar courses at the university level. Marketing Education Review, 21(3), 241-250.

Broadbent, J., \& Poon, W. L. (2015). Self-regulated learning strategies \& academic achievement in online higher education learning environments: A systematic review. The Internet and Higher Education, 27, 1-13.

Chang, C.-S., Liu, E. Z.-F., Sung, H.-Y., Lin, C.-H., Chen, N.-S., \& Cheng, S.-S. (2014). Effects of online college student's internet self-efficacy on learning motivation and performance. Innovations in Education and Teaching International, 51(4), 366-377. https://doi.org/10.1080/14703297.2013.771429

Chen, H., Islam, A. Y. M. A., Gu, X., Teo, T., \& Peng, Z. (2019). Technology-enhanced learning and research using databases in higher education: The application of the ODAS model. Educational Psychology. https://doi.org/10.1080/01443410.2019.1614149 
Chu, R. J. (2010). How family support and internet self-efficacy influence the effects of e-learning among higher aged adults - Analyses of gender and age differences. Computers \& Education, 55(1), 255-264.

Cochran, J. D., Baker, H. M., Benson, D., \& Rhea, W. (2016). Business student perceptions of online learning: Using focus groups for richer understanding of student perspectives. Organization Management Journal, 13(3), 149-166.

Dyrbye, L., Cumyn, A., Day, H., \& Heflin, M. (2009). A qualitative study of physicians' experiences with online learning in a master's degree program: Benefits, challenges, and proposed solutions. Medical Teacher, 31, e40-e46.

Dziuban, C., Moskal, P., Thompson, J., Kramer, L., DeCantis, G., \& Hermsdorfer, A. (2015). Student satisfaction with online learning: Is it a psychological contract? Online Learning, 19(2), 122-136. https://doi.org/10.24059/olj.v19i2.496

Endres, M. L., Chowdhury, S., Frye, C., \& Hurtubis, C. A. (2009). The multifaceted nature of online MBA student satisfaction and impacts on behavioral intentions. Journal of Education for Business, 84(5), 304-312.

Eom, S. B. (2012). Effects of LMS, Self-efficacy, and self-regulated learning on LMS effectiveness in business education. Journal of International Education in Business, 5(2), 129-144.

Eom, S. B., \& Ashill, N. (2016). The determinants of students' perceived learning outcomes and satisfaction in university online education: An update. Decision Sciences Journal of Innovative Education, 14(2), 185-215.

Francis, M. K., Wormington, S. V., \& Hulleman, C. (2019). The costs of online learning: Examining differences in motivation and academic outcomes in online and face-to-face community college developmental mathematics courses. Frontiers in Psychology, 10. https://doi.org/10.3389/fpsyg.2019.02054

Garratt-Reed, D., Roberts, L. D., \& Heritage, B. (2016). Grades, student satisfaction and retention in online and face-to-face introductory psychology units: A test of equivalency theory. Frontiers in Psychology, 7, 1-10.

Gaytan, J. (2015). Comparing faculty and student perceptions regarding factors that affect student retention in online education. American Journal of Distance Education, 29, 56-66. doi: $10.1080 / 08923647.2015 .994365$

Hammouri, Q., \& Abu-Shanab, E. (2018). Exploring factors affecting users' satisfaction toward Elearning systems. International Journal of Information and Communication Technology Education, 14(1), 44-57.

Hobson, T. D., \& Puruhito, K. K. (2018). Going the distance: Online course performance and motivation of distance learning students. Online Learning, 22(4), 129-140.

Hodges, C. B. (2008). Self-efficacy, motivational email, and achievement in an asynchronous math course. Journal of Computers in Mathematics and Science Teaching, 27(3), 265-285.

Horspool, A., \& Lange, C. (2012). Applying the scholarship of teaching and learning: student perceptions, behaviours and success online and face-to-face. Assessment \& Evaluation in Higher Education, 37(1), 73-88. 
Islam, A. Y. M. A., Leng, C. H., \& Singh, D. (2015). Efficacy of the Technology Satisfaction Model (TSM): An empirical study. International Journal of Technology and Human Interaction (IJTHI), 11(2), 45-60.

Jackson, L. C., Jones, S. J., \& Rodriguez, R. C. (2010). Faculty actions that result in student satisfaction in online courses. Journal of Asynchronous Learning Networks, 14, 78-96.

Jan, S. K. (2015). The relationships between academic self-efficacy, computer self-efficacy, prior experience, and satisfaction with online learning. American Journal of Distance Education, $29(1), 30-40$.

Jensen, S. A. (2011). In-class versus online video lectures: Similar learning outcomes, but a preference for in-class. Teaching of Psychology, 38(4), 298-302.

Joo, Y. J., Lim, K. Y., \& Kim, J. (2013). Locus of control, self-efficacy, and task value as predictors of learning outcome in an online university context. Computers \& Education, 62, 149-158.

Jung, H.-J. (2014). Ubiquitous learning: Determinants impacting learners' satisfaction and performance with smartphones. Language Learning \& Technology, 18(3), 97-119.

Kırmızı, Ö. (2015). The influence of learner readiness on student satisfaction and academic achievement in an online program at higher education. TOJET: The Turkish Online Journal of Educational Technology, 14(1), 133-142

Kokko, T., Pesonen, H., Kontu, E., \& Pirttimaa, R. (2015). Why study online in upper secondary school? Qualitative analysis of online learning experiences. Human Technology, 11(1), 57-70.

Kucuk, S., \& Richardson, J.C. (2019). A structural equation model of predictors of online learners' engagement and satisfaction. Online Learning, 23(2), 196-216. doi: 10.24059/olj.v23i2.1455

Kuo, Y.-C., \& Belland, B. R. (2016). An exploratory study of adult learners' perceptions of online learning: Minority students in continuing education. Educational Technology Research and Development, 64(4), 661-680.

Kuo, Y.-C., Walker, A. E., Belland, B. R., \& Schroder, K. E. E. (2013). A predictive study of student satisfaction in online education programs. International Review of Research in Open and Distance Learning, 14(1), 16-39.

Lai, C.-L., Hwang, G.-J., \& Tu, Y.-H. (2018). The effects of computer-supported self-regulation in science inquiry on learning outcomes, learning processes, and self-efficacy. Educational Technology Research and Development, 66(4), 863-892. https://doi.org/10.1007/s11423-0189585-y

Lederman, D. (2018, Nov 7). Online education ascends. Inside Higher Ed. https://www.insidehighered.com/digital-learning/article/2018/11/07/new-data-onlineenrollments-grow-and-share-overall-enrollment

Lee, Y., Choi, J., \& Kim, T. (2013). Discriminating factors between completers of and dropouts from online learning courses. British Journal of Educational Technology, 44(2), 328-337.

Lee, J. K. \& Hwang, C. Y. (2007). The effects of computer self-efficacy and learning management system quality on e-Learner's satisfaction. In L. Cameron, A. Voerman, \& J. Dalziel (Eds), Proceedings of the 2007 European LAMS Conference: Designing the future of learning (pp. 7379). LAMS Foundation.

Levy, Y. (2007). Comparing dropouts and persistence in e-learning courses. Computers \& Education, 48(2), 185-204. 
Li, N., Marsh, V., Rienties, B., \& Whitelock, D. (2017). Online learning experiences of new versus continuing learners: A large-scale replication study. Assessment \& Evaluation in Higher Education, 42(4), 657-672. https://doi.org/10.1080/02602938.2016.1176989

Liaw, S.-S., \& Huang, H.-M. (2013). Perceived satisfaction, perceived usefulness and interactive learning environments as predictors to self-regulation in e-learning environments. Computers \& Education, 60(1), 14-24.

Lim, C. K. (2001). Computer self-efficacy, academic self-concept, and other predictors of satisfaction and future participation of adult distance learners. American Journal of Distance Education, 15(2), 41-51.

Lin, Y.-M., Lin, G.-Y., \& Laffey, J. M. (2008). Building a social and motivational framework for understanding satisfaction in online learning. Journal of Educational Computing Research, $38(1), 1-27$.

Martin, F., Tutty, J. I., \& Su, Y. (2010). Influence of learning management systems self-efficacy on e-learning performance. Journal on School Educational Technology, 5(3), 26-35.

Nistor, N., \& Neubauer, K. (2010). From participation to dropout: Quantitative participation patterns in online university courses. Computers \& Education, 55(2), 663-672.

Pajares, F. (1996). Self-efficacy beliefs in academic settings. Review of Educational Research, 66(4), 543-578.

Palmer, S. R., \& Holt, D. M. (2009). Examining student satisfaction with wholly online learning. Journal of Computer Assisted Learning, 25(2), 101-113.

Palmer, S., \& Holt, D. (2010). Students' perceptions of the value of the elements of an online learning environment: Looking back in moving forward. Interactive Learning Environments, $18(2), 135-151$.

Parahoo, S., Santally, M., Rajabalee, Y., \& Harvey, H. (2016). Designing a predictive model of student satisfaction in online learning. Journal of Marketing for Higher Education, 26(1), 1-19.

Panadero, E., \& Alonso-Tapia, J. (2014). How do students self-regulate? Review of Zimmerman's cyclical model of self-regulated learning. Anales de Psicología, 30(2), 450-462.

Riley, K., \& Schmidt, D. (2016). Does online learning click with rural nurses? A qualitative study. Australian Journal of Rural Health, 24, 265-270.

Shen, D., Cho, M.-H., Tsai, C.-L., \& Marra, R. (2013). Unpacking online learning experiences: Online learning self-efficacy and learning satisfaction. The Internet and Higher Education, 19, $10-17$.

Simmering, M. J., Posey, C., \& Piccoli, G. (2009). Computer self-efficacy and motivation to learn in a self-directed online course. Decision Sciences Journal of Innovative Education, 7(1), 99-121.

Su, Y., Li, Y., Liang, J.-C., \& Tsai, C.-C. (2018). Moving literature circles into wiki-based environment: The role of online self-regulation in EFL learners' attitude toward collaborative learning. Computer Assisted Language Learning. doi: 10.1080/09588221.2018.1527363

Sun, J. C.-Y., \& Rueda, R. (2012). Situational interest, computer self-efficacy and self-regulation: Their impact on student engagement in distance education. British Journal of Educational Technology, 43(2), 191-204. 
Sun, Z., Xie, K., \& Anderman, L. H. (2018). The role of self-regulated learning in students' success in flipped undergraduate math courses. The Internet and Higher Education, 36, 41-53.

Waldman, L., Perreault, H., Alexander, M., \& Zhao, J. (2009). Comparing the perceptions of online learning between students with experience and those new to online learning. Information Technology, Learning, and Performance Journal, 25(2), 20-29.

Wang, C.-H., Shannon, D. M., \& Ross, M. E. (2013). Students' characteristics, self-regulated learning, technology self-efficacy, and course outcomes in online learning. Distance Education, 34(3), 302-323.

Wu, J.-H., Tennyson, R. D., \& Hsia, T.-L. (2010). A study of student satisfaction in a blended elearning system environment. Computers \& Education, 55(1), 155-164.

Yilmaz, R. (2017). Exploring the role of e-learning readiness on student satisfaction and motivation in flipped classroom. Computers in Human Behavior, 70, 251-260.

Zakariah, Z., Hashim, R. A., \& Musa, N. (2016). Motivation, experience, and satisfaction among adult learners with fully online web-based courses. Commonwealth of Learning. http://oasis.col.org/handle/11599/2548

Zimmerman, B. J. (1995a). Attaining reciprocality between learning and development through selfregulation. Human Development, 38(6), 367-372.

Zimmerman, B. J. (1995b). Self-regulation involves more than metacognition: A social cognitive perspective. Educational Psychologist, 30(4), 217-221.

Zimmerman, B. J. (2000). Attaining self-regulation: A social cognitive perspective. In M. Boekaerts, P. R. Pintrich \& M. Zeidner (Eds.), Handbook of self-regulation (pp. 13-40). Academic Press.

Zimmerman, W. A., \& Kulikowich, J. M. (2016). Online learning self-efficacy in students with and without online learning experience. American Journal of Distance Education, 30(3), 180-191.

Zimmerman, B. J., \& Martinez-Pons, M. (1988). Construct validation of a strategy model of student self-regulated learning. Journal of Educational Psychology, 80, 284-290.

Zimmerman, B. J., Schunk, D. H., \& DiBenedetto, M. K. (2017). The role of self-efficacy and related beliefs in self-regulation of learning and performance. In A. J. Elliot, C. S. Dweck, \& D. S. Yeager (Eds.), Handbook of competence and motivation: Theory and application (2nd ed., pp. 313-333). Guilford Press. 